\title{
ARTICLES
}

\section{Wounded Combatants, Military Medical Personnel, AND THE DILEMMA OF COLLATERAL RISK}

Geoffrey Corn ${ }^{*} \&$ Andrew Culliver ${ }^{* *}$

TABLE OF CONTENTS

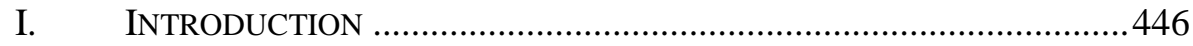

II. AN OVERVIEW OF THE IHL PROPORTIONALITY OBLIGATION.........447

A. The Concept of Lawful Military Objective ............................... 447

B. Explaining IHL Proportionality ..............................................450

III. THE PROPORTIONALITY DEBATE ....................................................452

A. Approach of the ICRC's 2016 Commentary to the GWS ..........452

B. The 2015 DoD Law of War Manual ......................................... 459

IV. The Humanitarian Basis FOR A MidDle-Ground

APPROACH ............................................................................ 464

V. THE 2016 LAW OF WAR MANUAL REVISION: EMBRACING THE

PRECAUTIONS APPROACH........................................................... 467

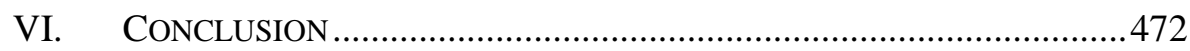

* Geoffrey Corn, LTC, USA, (ret.), is a Professor at South Texas College of Law Houston, and formerly Special Assistant for Law of War Matters and Chief of the Law of War Branch, Office of the Judge Advocate General, United States Army; Chief of International Law for US Army Europe; Professor of International and National Security Law at the US Army Judge Advocate General's School.

** Andrew Culliver, South Texas College of Law Houston, Class of 2017. 


\section{INTRODUCTION}

International Humanitarian Law (IHL) ${ }^{1}$ unquestionably obligates parties to a conflict to "respect and protect" wounded and sick members of the armed forces, as well as the military personnel, facilities, and transportation exclusively engaged in their collection and care (non-combatant members of the armed forces and their equipment and facilities). However, what seems less certain is how this obligation translates into protection from the harmful effects of actual combat operations-and furthermore, what the legal source and extent of such protection is. While it is axiomatic that the wounded and sick and those who care for them are protected from deliberate attack, it is equally axiomatic that significant harm may be inflicted on them as an incidental consequence of an attack on an otherwise lawful target. Is the attacking commander required to conduct a proportionality assessment based on this risk? If so, are these individuals and assets to be accorded the same weight as civilians and civilian objects? ${ }^{2}$ Must an attacking commander consider feasible precautions to mitigate the risk to these individuals and objects? Probing these questions exposes a rift in IHL interpretations of great potential significance for the protection of the wounded and sick and their caretakers.

A number of provisions of the U.S. Department of Defense (DoD) Law of War Manual indicate that military medical personnel, facilities, equipment, and military wounded and sick are not included within the scope of the IHL proportionality rule. $^{3}$ However, the International Committee of the Red Cross's (ICRC) new 2016 Commentary to the First Geneva Convention (GWS) takes a contrary view, indicating that both proportionality and precautions obligations extend to these people and objects. ${ }^{4}$ This Article

${ }^{1}$ In practice, International Humanitarian Law is used synonymously with Law of Armed Conflict (LOAC).

${ }^{2}$ It is both important to note and contrast that, where harm to civilians and/or civilian objects is an anticipated risk of an attack against a lawful military objective, the attacking force is unquestionably required to respect the prohibition against indiscriminate attacks, including compliance with the proportionality obligation. See Protocol Additional (I) to the Geneva Conventions of 12 Aug. 1949, and Relating to the Protection of Victims of International Armed Conflicts, June 8, 1977, 1125 U.N.T.S. 3, art. 51 [hereinafter AP I].

3 See generally U.S. DEP’T OF DEF., LAW OF WAR MANUAL §§ 7.3.3.1, 7.8.2.1, 7.10.1.1 (June 2015) [hereinafter DoD LAW OF WAR MANUAL].

${ }^{4}$ See generally Commentary on the First Geneva Convention: Convention (I) for the Amelioration of the Condition of the Wounded and Sick in Armed Forces in the Field (2d ed. 2016), paras. 1353-1357 [hereinafter 2016 Commentary GWS]. In 2016, the ICRC released an updated Commentary to the First Geneva Convention (GWS). This Commentary supplanted the original 1952 Commentary, which was the first of four similar Commentaries drafted from 1952 to 1960, all of which were published for each of the four Geneva Conventions. 
proposes that both of these interpretations are patently flawed. ${ }^{5}$ The DoD Manual's approach is preemptively dismissive of the obligation to protect the wounded and sick members of the armed forces, as well as those involved in their treatment. ${ }^{6}$ On the other hand, the ICRC's 2016 Commentary fails to contemplate the adverse effects of its asserted blanket extension of proportionality and precautionary obligations. ${ }^{7}$ Ultimately, it is the nearly century and a quarter year-old Martens Clause that sheds thoughtful direction on this topic.

\section{AN OVERVIEW OF THE IHL PROPORTIONALITY OBLIGATION}

At its core, IHL compliance is built upon several foundational principles: military necessity, humanity, distinction, and proportionality. ${ }^{8}$ Additionally, there is increasing recognition that the obligation to implement feasible precautions to mitigate civilian risk should also be included in this principles category. ${ }^{9}$ Though no treaty provides a dispositive definition of these principles, they are universally recognized as the baseline framework for regulating all armed conflicts. ${ }^{10}$ These principles function to ensure the employment of an efficient use of force that both accomplishes military objectives and minimizes the suffering associated with all armed conflict.

\section{A. The Concept of Lawful Military Objective}

While each of these cardinal principles is of irrevocable importance to the regulation of armed conflict, the principle central to the issue raised in this Article is IHL proportionality. However, to properly understand the function

\footnotetext{
${ }^{5}$ However, it cannot be stressed enough that the debate between these two sources has no relevance to the question of whether the civilian medical personnel, facilities, or wounded and sick fall within the scope of the LOAC/IHL proportionality (and furthermore, precautions) obligations. As civilians and civilian objects, there can be no doubt about the affirmative answer to this question.

6 See generally DoD LAW OF WAR MANUAL, supra note 3, §§ 7.3.3.1, 7.8.2.1, 7.10.1.1.

7 See generally 2016 Commentary GWS, supra note 4, paras. 1353-1357.

8 DoD LaW of War Manual, supra note 3, § 2.1; Manual of the LaW of ARmed Conflict $\$ 2.1$ (U.K. Ministry of Defence ed., Oxford, 2004) [hereinafter UK LOAC MANUAL]. The United States and the United Kingdom apply each of these principles to all military operation. Both have devoted an entire chapter of their respective military manual to the explanation of these principles. This is a common thread found in nearly all military manuals, with some variation as to the respective principles listed.

${ }^{9}$ See Jean-Marie Henckaerts \& Louise Doswald-Beck, Customary International Humanitarian Law, Volume I. Rules, Chapters 5-6, Cambridge University Press, 2009, https:// www.icrc.org/eng/assets/files/other/customary-international-humanitarian-law-i-icrc-eng.pdf.

${ }^{10}$ See UK LOAC ManuAL, supra note 8, ๆ 2.1; see also Henckaerts \& Doswald-Beck, supra note 9 , at xxii.
} 
of proportionality, it is first necessary to begin with a discussion of proportionality's relationship to the principle of distinction, and more specifically, to the IHL concept of lawful military objective. The reason for this is because proportionality considerations arise only after the determination that an intended object of attack is a military objective: that a person, place, or thing qualifies as a lawful military target (or objective). ${ }^{11}$ It is only after such determination that proportionality demands assessment of potential incidental death, injury, or destruction to civilians and civilian objects. ${ }^{12}$

Pursuant to the principle of distinction, lethal combat power may only be directed at lawful targets. ${ }^{13}$ Targets can generally be broken down into "persons" and "things," the latter of which need not be explained for purposes of this Article. With regard to persons, most of the international community recognizes two categories: "combatants," and "civilians" (frequently referred to as "non-combatants," a term that is technically inaccurate as it instead denotes non-combatant members of the armed forces: medical personnel and chaplains exclusively engaged in the collection and care of the wounded and sick). ${ }^{14}$ The rule regarding civilians is clear: civilians are not to be made the deliberate object of attack, unless and only for such time as they take a direct part in hostilities. ${ }^{15}$ On the other hand, combatants-as defined through a complex interrelationship of treaty

\footnotetext{
11 See DoD LAW OF WAR MANUAL, supra note 3, $\S 5.12 .1$ (specifically, the Manual provides, "In conducting attacks, the proportionality rule only need be applied when civilians or civilian objects are at risk of harm from attacks on military objectives").

12 See AP I, supra note 2, art. 57(2)(a)(iii), (2)(b) (although the approach of the ICRC's 2016 Commentary to the GWS would extend this protection to any person or object not subject to lawful deliberate attack 2016 Commentary GWS, supra note 4, para. 1357).

${ }^{13}$ Id. art. 48.

14 UK LOAC MANUAL, supra note 8, ๆๆ 4.1-4.1.1. The United States further complicates this by loosely claiming there to be a category of "unprivileged belligerents," that fail to enjoy the benefits of civilians or combatants because of their membership in an unlawful armed group. See DoD LAW OF WAR MANUAL, supra note 3, § 4.3.1. This interpretation is highly controversial, and most nations observe an alternative approach offered by the ICRC rooted in the theory of "continuous combatant function" relating to civilians directly participating in hostilities. See Nils Melzer, InTerpretive Guidance on the Notion of Direct PARTICIPATION IN HOSTILITIES UNDER INT’L HUMANITARIAN LAW 77 (May 2009).

15 See AP I, supra note 2, arts. 50-51. Article 51(2) specifically states: "[T] he civilian population as such, as well as individual civilians, shall not be the object of attack. Acts or threats of violence the primary purpose of which is to spread terror among the civilian population are prohibited.” Id. art. 51(2). But furthermore, Article 50(1) widens the effect of such a provision by stating that, "[i]n case of doubt whether a person is a civilian, that person shall be considered a civilian.” Id. art. 50(1). Direct participation in hostilities is a more complex discussion, but is beyond the scope of this Article.
} 
provisions culminating with Article 43 of Additional Protocol I, are targetable at all times because of their combatant status. ${ }^{16}$

The legal authority to attack combatants terminates, however, when the combatant is rendered wounded or sick within the meaning of IHL. ${ }^{17}$ Specifically, pursuant to Article 12 of the GWS, wounded and sick members of the armed forces are to be respected and protected in all circumstances, and therefore deemed unlawful targets. ${ }^{18}$ However, not every illness or injury results in vesting the combatant with this cloak of protection. The 2016 Commentary explains that the term wounded and sick is best understood through the following two conditions:

[1] The decisive criterion for determining when a person is wounded or sick in the sense of Article $12 \ldots$ is that of being in need of medical care. It is this particular need, and the specific vulnerability that comes with it, that the legal regime protecting the wounded and sick aims to address.

[2] In addition to being in need of medical care, in order to qualify as wounded or sick in the sense of Article 12, a person must also refrain from any act of hostility. Thus, contrary to the ordinary meanings of the terms 'wounded' and 'sick', persons who continue to engage in hostilities do not qualify as wounded or sick under humanitarian law, no matter how severe their medical condition may be. ${ }^{19}$

Wounded and sick members of the armed forces do not lose their status as combatants. $^{20}$ Instead, their condition is better understood as vesting them with a cloak of protection for the time that they are wounded and sick. Once recovered, that protection terminates and they are again subject to deliberate attack. $^{21}$ If captured, they are prisoners of war for the entire duration of

\footnotetext{
16 AP I, supra note 2, art. 43; Geneva Convention for the Amelioration of the Condition of the Wounded and Sick in Armed Forces in the Field, Aug. 12, 1949, art. 4(A)(1), (2), (3), (6), U.S.T. 3114, 75 U.N.T.S. 970 [hereinafter GWS].

${ }^{17}$ GWS, supra note 16 , art. 12.

${ }^{18}$ Id.

192016 Commentary GWS, supra note 4, paras. 1342-1345.

20 See id. paras. 1341-1351.

${ }^{21}$ See id. paras. 1345-1351.
} 
captivity, with special protections derived from being wounded and sick. ${ }^{22}$ Most importantly, the protection afforded to wounded and sick combatants in no way transforms them into civilians, or transforms their status into that of a civilian, while they are wounded and sick. ${ }^{23}$ Instead, they exist as a special category of members of an armed force that, for the duration of their tenure as wounded or sick, are protected from being made the object of attack. ${ }^{24}$

Distinct from both combatants and civilians are what IHL classifies as non-combatant members of the armed forces. These are members of the armed forces-military personnel-who are exclusively engaged in the humanitarian function of search for, collection, and care of the wounded and sick. $^{25}$ This category of non-combatants is defined by Article 24 of the GWS, which provides:

Medical personnel exclusively engaged in the search for, or the collection, transport or treatment of the wounded or sick, or in the prevention of disease, staff exclusively engaged in the administration of medical units and establishments, as well as chaplains attached to the armed forces, shall be respected and protected in all circumstances. ${ }^{26}$

Like wounded and sick combatants, non-combatant members of the armed forces must be respected and protected at all times, so long as they do not commit an "act harmful to the enemy" that is inconsistent with their exclusive "humanitarian duties." 27 This same protection extends to their facilities and equipment. ${ }^{28}$

\section{B. Explaining IHL Proportionality}

With this basic understanding of lawful targets in mind, the relevance and application of the proportionality obligation vis-à-vis the wounded and sick and non-combatant members of the armed forces can be more accurately

\footnotetext{
${ }^{22}$ Id. art. 14, paras. 4-6 ("When wounded or sick prisoners of war have recovered, the First Convention no longer applies to them, but they remain protected by the Third Convention until the moment specified in Article 5 of that Convention-their final release and repatriation.”). See also DoD LAW OF WAR MANUAL, supra note 2, § 7.3.3.3 (iterating that the "wounded, sick, and shipwrecked must be respected and protected").

${ }^{23}$ Cf. 2016 Commentary GWS, supra note 4, art. 14, paras. 4-6.

24 See id.

25 GWS, supra note 16, art. 24.

${ }^{26}$ Id.

272016 Commentary GWS, supra note 4, paras. 1995-1996.

${ }^{28}$ GWS, supra note 16, art. 33.
} 
understood. The DoD Law of War Manual describes the "proportionality rule" in the following manner: "[c]ombatants must refrain from attacks in which the expected loss of life or injury to civilians, and damage to civilian objects incidental to the attack, would be excessive in relation to the concrete and direct military advantage expected to be gained." ${ }^{29}$ The United Kingdom's Law of Armed Conflict Manual from the Ministry of Defence offers a similar definition, stating, "[t]he principle of proportionality requires that the losses resulting from a military action should not be excessive in relation to the expected military advantage."30 These general definitions of the proportionality obligation are in large measure superseded by the more specific enumeration of the rule in Article 57(2)(a)(iii) and (2)(b) of Additional Protocol I:

a) those who plan or decide upon an attack shall:

...

iii) refrain from deciding to launch any attack which may be expected to cause incidental loss of civilian life, injury to civilians, damage to civilian objects, or a combination thereof, which would be excessive in relation to the concrete and direct military advantage anticipated;

b) an attack shall be cancelled or suspended if ... the attack may be expected to cause incidental loss of civilian life, injury to civilians, damage to civilian objects, or a combination thereof, which would be excessive in relation to the concrete and direct military advantage anticipated; ${ }^{31}$

Accordingly, the proportionality obligation functions to protect civilians and civilian property that are reasonably assessed as subject to the harmful effects of an attack on a proximate lawful military objective-what the law characterizes as "incidental" injury or "collateral" damage. ${ }^{32}$ This protection takes the form of a prohibition against launching an attack on such an objective when the anticipated harm to civilians and/or civilian property is assessed as excessive in comparison to the anticipated "concrete and direct"

${ }^{29}$ DOD LAW OF WAR MANUAL, supra note 3, § 5.12.

30 UK LOAC MANUAL, supra note 8, 92.6.

31 AP I, supra note 2, art. 57(2)(a)(iii), (2)(b) (emphasis added) (notice the specific qualification of "civilian" in the definition, as well as the term "excessive"). Article 57 is widely accepted as reflective of customary international law.

${ }^{32}$ Id. 
military advantage to be gained from the attack. As Article 51(5)(b) of AP I indicates, an attack that violates the proportionality principle is considered indiscriminate and therefore unlawful. ${ }^{33}$

There is simply no question that this proportionality obligation is triggered whenever an attack is anticipated to jeopardize civilian wounded and sick or civilian medical personnel and/or facilities. ${ }^{34}$ It is the civilian status of such individuals and objects—and not the fact that such individuals and facilities are associated with humanitarian protections focused on ameliorating the suffering of the wounded and sick-that implicates the obligation. What is less clear, however, is whether the obligation also extends to protect military medical personnel, wounded and sick combatants, and military medical facilities. This uncertainty is central to the questions raised above: how, if at all, does the presence of wounded and sick combatants and military medical personnel and facilities impact the legality of attacking proximate lawful objects of attack? Is an attacking commander required to conduct a proportionality assessment based the anticipated risk that these individuals and facilities will suffer the incidental and collateral consequences of the attack? Is a commander obligated to forego an attack if she assesses that the risk is excessive compared to the concrete and direct anticipated military advantage? If so, is the weight accorded to these military personnel and assets identical to the weight accorded to civilians and civilian property when implementing the proportionality balance? Furthermore, if the proportionality obligation extends to protect these individuals and objects, does this mean the precautions obligation is also implicated? Must a commander consider the feasible precautions to mitigate the risk to these individuals and objects? As is indicated below, the ICRC's 2016 Commentary to the GWS and the DoD Manual provide conflicting answers to these questions.

\section{The Proportionality DeBATE}

\section{A. Approach of the ICRC's 2016 Commentary to the GWS}

In March 2016, the International Committee of the Red Cross released an updated Commentary to the First Geneva Convention of $1949 .{ }^{35}$ Among the many additions to the new Commentary is a discussion of the principle of

${ }^{33}$ See id. art. 51(5)(b).

${ }^{34}$ See id. art. 57(2)(a)(iii), (2)(b); see also Geneva Convention Relative to the Protection of Civilian Persons in Time of War, Aug. 12, 1949, art. 16, 18, 20, 6 U.S.T. 3516, 75 U.N.T.S. 973 [hereinafter GC].

35 See generally 2016 Commentary GWS, supra note 4, Foreword. 
proportionality as it pertains to the wounded and sick members of the armed forces (and, by implication, military medical personnel and facilities), located within the Commentary's discussion of Article 12(1)'s "respect and protect" clause. Specifically, the Commentary indicates that:

A question that arises is whether the obligation to respect the wounded and sick entails that they must be taken into consideration for the purposes of the proportionality assessment. This is controversial and of particular relevance in the context of Article 12, which refers exclusively to wounded and sick members of the armed forces and other persons mentioned in Article 13 [establishing the qualification criteria for non-combatant members of the armed forces]. ${ }^{36}$

As is noted extensively throughout the Commentary to Article 12, there is no existing treaty provision that indicates any member of the armed forceseven those who are wounded and sick and protected by the GWS or noncombatant members of the armed forces-fall within the scope of the proportionality obligation. For example, the Commentary indicates that:

Article 51(5)(b) of Additional Protocol I, which is part of a specific chapter on 'Civilians and Civilian Protection', mentions civilians but not the wounded and sick specifically. ${ }^{37}$

The omission of the wounded and sick from this provision might have been for editorial reasons, given the subject matter of the chapter, rather than the intentional exclusion of certain categories of protected persons from the proportionality assessment.

The preparatory work for Article 12 is silent on the matter. ${ }^{38}$ This is not surprising given that in 1949 the relevant rules regarding the conduct of hostilities had not been spelled out in as much detail as they are today. However, one might have expected such a discussion in 1977, when simultaneously both the obligation to respect and protect the wounded and sick (Article 10 of Additional Protocol I) and specific rules pertaining to the conduct of hostilities (Articles 51, 57 and 58

${ }^{36}$ Id. para. 1355.

${ }^{37}$ Id.

38 See IAn Henderson, The Contemporary Law of TARgeting 196 (2009). See further Laurent Gisel, Can the incidental killing of military doctors never be excessive?, 95 INT'L R. RED CROss 215 (2013). 
of Additional Protocol I) were at issue. Nevertheless, the preparatory work for Article 10 of the Protocol is likewise silent on the matter. ${ }^{39}$

Nonetheless, contrary to the express terms of relevant treaty provisions, the Commentary authors suggest that the weight of IHL itself demands that these individuals be considered to fall within the scope of the proportionality obligation:

[I]n view of the specific protections accorded to the wounded and sick, namely the obligation to respect (and to protect) them in all circumstances, a fortiori they should also benefit from the protection accorded to civilians. In other words, if civilians are to be included in the proportionality assessment all the more so should the wounded and sick. ${ }^{40}$

Thus, with regard to wounded and sick members of the armed forces, and, by implication, non-combatant members of the armed forces, the 2016 Commentary answers the proportionality applicability question in the affirmative. Indeed, the Commentary specifically indicates that "the presence of wounded and sick members of the armed forces in the vicinity of a military objective is to be taken into consideration when carrying out a proportionality assessment prior to an attack."41

There is no denying that the Commentary interpretation does, on the surface at least, seem logical from a humanitarian perspective. After all, what good is a strict prohibition on the targeting of the wounded and sick members of the armed forces if there is no accordant obligation to include them within the assessment of impermissible incidental harm anticipated from an otherwise lawful attack? As the Commentary notes:

Indeed, if the wounded and sick were not to be considered for purposes of the proportionality principle, their presence in the vicinity of legitimate military objectives would be legally irrelevant. However, this would contradict the explicit obligation to respect them in all circumstances and the basic rationale of according special protection to them. It would be unreasonable to consider that direct or indiscriminate attacks against the wounded and sick would be strictly prohibited and

392016 Commentary GWS, supra note 4, paras. 1355-1356.

${ }^{40}$ Id. para. 1357.

${ }^{41}$ Id. 
would amount to a grave breach, while incidental harm and even excessive incidental casualties would not be prohibited. ${ }^{42}$

But one need not drill too deeply to call this logic into question. As noted above, even the Commentary recognizes that nothing in the text, or the preparatory work of AP I validates the extension of the proportionality obligation beyond civilians and civilian objects to this category of individuals and objects. ${ }^{43}$ In fact, the plain text of AP I contradicts this extension, as the proportionality rule is expressly intended to protect only the civilian population, ${ }^{44}$ a category that does not include members of the armed forces. Because qualifying as wounded and sick pursuant to Article 12 of the GWS, or as a non-combatant member of the armed forces pursuant to Article 13 of the GWS in no way transforms members of the armed forces into civilians, the relevant proportionality treaty rules are simply inapplicable.

By invoking an a fortiori rationale for the asserted extension of the proportionality obligation, the Commentary ironically acknowledges the invalidity of the extension it proposes. ${ }^{45}$ The Commentary asserts that the "greater" obligation from which this "lesser" obligation flows- the lesser obligation being the proportionality obligation-is the "obligation to respect and protect" cited in Article 10 of AP I and Article 12 of GWS. ${ }^{46}$ However, this a fortiori rational is inherently self-contradictory. The proportionality obligation cannot be reconciled with the obligation to respect and protect because "[r]espect means 'to spare, not to attack', while protect means 'to come to someone's defence, to lend help and support." "47 In contrast, any extension of the proportionality rule inherently allows for the infliction of death or injury, provided that the extent of this anticipated incidental death and injury is not assessed as excessive in relation to the anticipated military advantage from an attack. In other words, an extension of the proportionality obligation to members of the armed forces falling under the scope of Articles 12 and 13 of the GWS for the reason proffered by the Commentary is a contradiction in and of itself. While the humanitarian extension may be reasonably appealing, the Commentary's rational is in fact illogical, as the

${ }^{42} \mathrm{Id}$.

43 Id. para. 1356.

44 See AP I, supra note 2, arts. 50-51, 57.

452016 Commentary GWS, supra note 4, para. 1357 ("However, in view of the specific protections accorded to the wounded and sick, namely the obligation to respect (and to protect) them in all circumstances, a fortiori they should also benefit from the protection accorded to civilians.”).

${ }^{46} I d$.

47 Commentary on the Additional Protocols of 8 June 1977 to the Geneva Conventions of 12 August 1949, para. 446 (Yves Sandoz et al. eds., 1987); see also AP I, supra note 2, art. 10. 
supposed "lesser" obligation is a direct contradiction to the "greater" obligation suggested by the ICRC's a fortiori rationale.

Furthermore, the Commentary's approach fails to address several additional, complex questions that arise as the result of extending proportionality to protect wounded and sick members of the armed forces and military medical objects. For example, can or should wounded and sick members of the armed forces and those who care for them be ipso facto equated with civilians? When assessing the consequence of anticipated incidental injury and collateral damage, is the weight accorded to these individuals and objects identical to that of civilians and civilian objects? Does the humanitarian underpinning of the extension justify a more restrictive application of proportionality, or does the inherent military nature of these individuals and objects justify a diminished proportionality protection? In any event, what is the legal basis for even resolving these questions once it is conceded that the proportionality obligation never contemplated addressing concerns associated with protecting military personnel and equipment? Finally, how is the calculation of permissible harm to be guided? Does it apply in all operational and tactical situations? Is it limited to only post-evacuation contexts? Does it arise the moment the combatant is considered wounded and sick, or is there some necessary delay between initial incapacitation and application of the protection?

The Commentary fails to adequately consider these complexities. This is not surprising, as an effort to address the complexities almost immediately exposes the inherent inconsistencies between extending the proportionality rule to these individuals and facilities and their association with the armed forces. Most problematic, however, is the Commentary's failure to address the question of timing. Specifically, at what point does the proportionality obligation become applicable? Does it arise whenever there is actual knowledge that wounded and sick combatants and/or non-combatant members of the armed forces are proximate to an anticipated target, or perhaps even when a reasonable attacking commander should anticipate such presence? An affirmative answer to this question seems inherently unworkable. For example, engaging an enemy force will often result in immediate actual knowledge that casualties were inflicted, or at least a high probability of such an outcome. Indeed, the military decision-making process relies on predictions of enemy casualty rates to inform anticipated force ratios in the operational planning process. Knowledge of enemy order of battle will frequently indicate that non-combatant members of the armed forces are co-mingled with combatants.

Consider a hypothetical engagement between the armed forces of the United States and Iraq. While making a southerly approach towards 
Baghdad, the U.S. commander receives reliable intelligence that a large number of Iraqi Revolutionary Guard members are fortifying the east bank of the Euphrates River in an effort to hold the American advance before they can cross. In response, the U.S. commander orders a massive combined arms bombardment of enemy positions along the sparsely populated east bank. Now imagine that the initial post-fire assessment indicates that a significant number of Iraqi troops have been injured, but that intelligence also indicates movement by Revolutionary Guard reinforcements to the area to bolster the defense of the river. If a proposed proportionality obligation arises as soon as an enemy combatant is rendered wounded and sick, then every attack decision following the "first salvo" would require a proportionality assessment. This approach would require the U.S. commander to postpone a subsequent attack decision in order to first conduct a proportionality assessment to protect the wounded Iraqi soldiers and military medical personnel in the target area.

While the humanitarian objective of sparing the wounded and sick additional suffering and protecting those exclusively engaged in their collection and care might render this outcome appealing, it is simply inconsistent with the traditional approach to conducting hostilities. Indeed, it seems implausible that state practice supports such an extension of the proportionality obligation. An inherent flaw in the concept is exposed by this hypothetical: it fails to account for the true nature of status-based targeting of enemy assets. The commander in our hypothetical is not making attack decisions based on individualized threat assessments. Instead, he is attacking the enemy in its collective capacity, seeking to render the enemy unit as combat ineffective. Injecting a proportionality obligation into the overall process of executing the attack will undermine the commander's ability to press tactical advantage and set the tempo of the engagement in order to maximize the collective impact on the enemy force. Such an application of the proportionality obligation would therefore be entirely inconsistent with the nature of combat operations, and furthermore, IHL itself. For, as is noted in the UK Law of War Manual, "The law of armed conflict is consistent with the economic and efficient use of force. It is intended to minimize the suffering caused by armed conflict rather than impede military efficiency."

It may be an unfortunate necessity of combat that wounded, sick, and non-combatant members of the armed forces remain exposed to the collateral

\footnotetext{
48 U.K Ministry of Defence, The Joint Service Manual on the Law of Armed Conflict, JSP 383, para. 2.1., at 21 (2004), https://www.gov.uk/government/uploads/system/uploads/att achment_data/file/27874/JSP3832004Edition.pdf.
} 
consequences of attacks directed against the units they are associated with, but this is consistent with the traditional balance between necessity and humanity manifested in the GWS and AP I. ${ }^{49}$ These treaties impose important limitations on the conduct of hostilities to protect the wounded, sick, and military medical personnel and facilities. But unlike application of the proportionality obligation, these obligations are consistent with the inherent necessities of the conduct of hostilities. There is simply no legitimate necessity in directing an attack against an enemy combatant who is incapable of participating in hostilities as the result of wounds or sickness. Necessity cannot justify directing an attack at members of the armed forces (and their facilities) exclusively engaged in the humanitarian function of collecting and caring for the wounded and sick because the individuals they aid are no longer capable of contributing to enemy combatant activities (and of course, once returned to service as combatants, attack authority is logically resurrected). None of these prohibitions compromise the effectiveness of combat operations against enemy forces. As noted above, the same cannot be said for the proportionality obligation.

While the incompatibility of extending a proportionality obligation to military personnel and assets during combat engagements may be obvious, the matter becomes more nuanced as the medical response begins to materialize. This nuance may suggest that applicability of the proportionality obligation should depend on crossing some tactical demarcation. While this might be responsive to the concerns addressed above, it still raises serious practical and theoretical complexities. From a practical standpoint, identifying the proportionality "trigger point" would be both difficult and inherently arbitrary. Would the obligation arise at the moment the wounded and sick are collected by military medical personnel? Or does it arise when they reach the field medical station, or the combat support hospital? Should applicability be based on conclusive demarcation points or would they be merely guidelines subject to a totality of the circumstances assessment? How would the tempo of combat operations factor into this assessment? The Commentary completely fails to address this issue, and simply overlooks the complexity of this timing question. ${ }^{50}$

\footnotetext{
49 AP I, supra note 3, part II.

50 The 2016 Commentary also suggests that "on the basis of the same rationale, an attacker must take precautions in accordance with Article 57 of Additional Protocol I in relation not only to civilians but also to wounded and sick members of the armed forces, to protect them from direct attack and collateral damage.” 2016 Commentary GWS, supra note 4, para. 1357. While also problematic, the warning component of the precautionary obligation is less concerning, as AP I expressly indicates that a warning is not required if circumstances do not permit. AP I, supra note 2, art. 57(c). However, there are unanswered questions specific to the precautionary obligation as well. For example, in the civilian context, AP I requires that
} 
The theoretical flaw in a qualified application of the obligation is also significant. Limiting application of the obligation to only certain tactical and operational situations creates an inherent humanitarian inconsistency: the protection is not based on status, but instead on the situation. When applied as intended to protect civilians and civilian property, the proportionality obligation is purely status based, it applies based on the status of the individuals and/or property subjected to risk, and is not qualified based on where or when this risk arises. If, as the Commentary asserts, application of the proportionality obligation to military wounded, sick, and medical personnel and facilities is derived from the respect and protect obligation, then it, like application to civilians and civilian property, must be exclusively status based. It is impossible to reconcile application of the protection in some tactical circumstances but not others with the premise that it is derived from the obligation to respect and protect.

Ultimately, while the objective of protecting military wounded, sick, and medical personnel and facilities from the incidental effects of combat operations is a logical humanitarian goal, reliance on an extension of the proportionality rule to achieve this goal is illogical. This does not, however, mean that consideration of risk to such individuals and facilities is irrelevant in the attack decision-making process. This opposite end of the protection spectrum is reflected in the 2015 DoD Law of War Manual.

\section{B. The 2015 DoD Law of War Manual}

The 2015 Department of Defense Law of War Manual adopted the opposite approach to the question of extending proportionality protection to wounded and sick members of the armed forces, as well as military medical and religious personnel (an approach that remains unchanged in the 2016 revision to the Manual, discussed in Part V). The 2015 Manual indicated in several paragraphs that these personnel ${ }^{51}$ and objects did not fall within the scope of the proportionality obligation. ${ }^{52}$ For example, paragraph 7.3.3.1 of the 2015 Manual directed that:

when there is a choice between two methods of attaining a similar military objective, the one that poses the least risk to civilians must be selected. $I d$. The Commentary's suggestion of a precautionary obligation presumably includes such a requirement specific to those rendered wounded and sick, when blended with the timing concerns addressed earlier, presents a potential hindrance to a commander's ability to effectively wage war.

51 Such personnel are often referred to as "non-combatant members of the armed forces." Int'l Comm. of the Red Cross, Customary IHL Database, Rule 3 (Feb. 24, 2017), https://ihl-da tabases.icrc.org/customary-ihl/eng/docs/v1_rul_rule3.

52 DoD LaW OF WAR MANUAL, supra note 3, §§ 7.3.3.1, 7.8.2.1, 7.10.1.1. 
The respect and protection due to the wounded, sick, and shipwrecked do not cover incidental damage or casualties due to proximity to military objectives or to a justifiable mistake. Because combatants who are wounded, sick, or shipwrecked on the battlefield are deemed to have accepted the risk of death or further injury due to proximity to military operations, they need not be considered as incidental harm in assessing proportionality in conducting attacks. ${ }^{53}$

This assertion may seem inconsistent with the overarching rule enumerated in paragraph 7.3:

Members of the armed forces and other persons mentioned in Article 13 of the GWS and the GWS-Sea, who are wounded, sick, or shipwrecked, shall be respected and protected in all circumstances. Such persons are among the categories of persons placed hors de combat; making them the object of attack is strictly prohibited. ${ }^{54}$

However, contrasting these two paragraphs reveals the clear distinction that the 2015 Manual drew between protecting wounded and sick combatants from deliberate attack, and protecting them from the incidental consequences of deliberate attack directed against proximate lawful targets. The former is prohibited in accordance with the express terms of the GWS; the latter is expressly excluded from the protective regime of the Manual.

${ }^{53} I d$. $§$ 7.3.3.1. This particular provision is specifically referencing the individuals who fall within the relevant definitions of the First and Second Geneva Conventions, and not civilian wounded and sick, when stating "wounded, sick, and shipwrecked.” See id. § 7.3.

To contrast, the 2016 DoD Manual includes the following language, with the italicized portion identifying that language remaining unchanged:

The respect and protection due to the wounded, sick, and shipwrecked do not prohibit incidental damage or casualties due to their proximity to military objectives or to a justifiable mistake. Combatants who are wounded, sick, or shipwrecked on the battlefield are deemed to have accepted the risk of death or further injury due to their proximity to military operations. Although the presence of the wounded, sick, or shipwrecked on the battlefield does not serve to exempt military objectives from attack due to the risk that such personnel would be incidentally harmed, feasible precautions must be taken to reduce the risk of harm to the wounded, sick, or shipwrecked.

See U.S. DeP’T of DeF., LAW OF WAR Manual 7.3.3.1 (June 2015, updated Dec. 2016) [hereinafter DoD LaW of War MAnual, Dec. 2016 ed.] (emphasis added). See also Part V for a more detailed discussion of the 2016 Manual's changes.

54 Dod LAW OF WAR MAnual, Dec. 2016 ed., supra note 53 (emphasis added) (footnote omitted). 
Accordingly, there was no inconsistency between the "strictly prohibited" language of paragraph 7.3 and the subsequent indication that wounded and sick combatants are in no way relevant to proportionality considerations.

Similarly, paragraph 7.10.1 indicated that military medical units and facilities, "must not knowingly be attacked, fired upon, or unnecessarily prevented form discharging their proper function," the key term being knowingly. This paragraph aligned with the overall scheme of the Manual's treatment of military wounded and sick, medical personnel, and facilities, as it prohibited making such units or facilities the object of attack. However, as with wounded and sick combatants, paragraph 7.10.1.1 indicated that, “[t]he incidental harm to medical units or facilities, due to their presence among or proximity to combatant elements actually engaged by fire directed at the latter, gives no just cause for complaint." ${ }^{55}$ And as was the case with the military wounded and sick, the rational provided was that "medical units and facilities that are positioned near military objectives are deemed to have accepted the risk of death or further injury due to proximity to military operations" and therefore, "they need not be considered as incidental harm in assessing proportionality in conducting attacks"56

Finally, the 2015 DoD Manual approach offered yet again the same rule and rational when addressing risk to non-combatant members of the armed forces. Like military wounded and sick, paragraph 7.8 indicated that such personnel are to be respected and protected. ${ }^{57}$ However, paragraph 7.8.2.1 emphasized that this obligation did not include a proportionality constraint:

${ }^{55}$ Id. § 7.10.1.1. In the 2016 DoD Manual, the quoted language remained unchanged. See DoD LAW OF WAR MANUAL, Dec. 2016 ed., supra note 53, § 7.10.1.1.

56 DoD LaW OF War Manual, supra note 3, § 7.10.1.1. In the 2016 DoD Manual, the quoted language remains unchanged. However, as with 7.3.3.1, the language directly subsequent the above quote from 7.10.1.1 has been altered. The unaltered portion is italicized for convenience:

The incidental harm to military medical units or facilities, due to their presence among or in proximity to combatant elements actually engaged, by fire directed at the latter, gives no just cause for complaint. Commanders are obligated to situate military medical units and facilities such that they are not in danger from attack against military objectives. Military medical units and facilities that are positioned near military objectives are deemed to have accepted the risk of harm due to their proximity to military operations. Although the presence of military medical units and facilities does not serve to exempt nearby military objectives from attack due to the risk that military medical units and facilities would be incidentally harmed, feasible precautions must be taken to reduce the risk of harm to military medical units and facilities.

See DoD LaW OF War Manual, Dec. 2016 ed., supra note 53, § 7.10.1.1.

57 DoD LAW OF WAR MANUAL, supra note 3, § 7.8. 
The incidental killing or wounding of such personnel, due to their presence among or in proximity to combatant elements actually engaged by fire directed at the latter, gives no just cause for complaint. Because medical and religious personnel are deemed to have accepted the risk of death or further injury due to proximity to military operations, they need not be considered as incidental harm in assessing proportionality in conducting attacks. ${ }^{58}$

Now, because paragraphs 7.3.3, 7.8.2, and 7.10.1 indicated that "respect and protection" means "that they [protected military personnel like the wounded and sick, and non-combatant members of the armed forces] should not be knowingly attacked, fired upon, or unnecessarily interfered with,"59 it may be possible to imply a proportionality consideration. This is because proportionality assessments by their very nature involve attack judgments informed by the knowledge of incidental injury or collateral damage. ${ }^{60}$ However, in the case of the 2015 DoD Manual, it is implausible to read the prohibition against "knowingly" attacked or "unnecessarily interfered with" as a subtle opening to extend a Commentary-like proportionality rule to these personnel. Paragraphs 7.3.3, 7.8.2, and 7.10.1 cannot be read in isolation, but instead alongside the paragraphs directly following them, 7.3.3.1, 7.8.2.1, and 7.10.1.1, which expressly rejected the application of the proportionality obligation with regard to these personnel. Consistent with the discussion above, this seems to confirm that the DoD Manual used the term "knowingly" as a synonym for deliberately.

Taken together, these provisions of the 2015 DoD Manual indicated that the emphasis on knowledge in relation to the respect and protect obligation was not intended to suggest a prohibition on the knowing infliction of

${ }^{58}$ Id. § 7.8.2.1. Again to contrast, the 2016 DoD Manual includes the following language, with the italicized portion identifying that language remaining unchanged:

The incidental killing or wounding of such personnel, due to their presence among or in proximity to combatant elements actually engaged by fire directed at the latter, gives no just cause for complaint. Medical and religious personnel are deemed to have accepted the risk of death or injury due to their proximity to military operations. Although the presence of medical and religious personnel does not serve to exempt nearby military objectives from attack due to the risk that military medical and religious personnel would be incidentally harmed, feasible precautions must be taken to reduce the risk of harm to military medical and religious personnel.

See DoD LaW of War Manual, Dec. 2016 ed., supra note 53, § 7.8.2.1.

59 DoD LAW OF WAR MANuAL, supra note 3, §§ 7.3.3, 7.8.2, 7.10.1 (emphasis added).

${ }^{60}$ Valerie Epps, Civilian Casualties in Modern Warfare: The Death of the Collateral Damage Rule, 41 GA. J. INT’L \& CoMP. L. 307, 330 (2013). 
incidental injury and/or collateral damage - the type of harm implicated by the proportionality obligation. Instead, they indicated a prohibition on launching an attack knowing that it is directed against protected personnel or objects. The DoD Manual clearly acknowledged that commanders will often have knowledge that military wounded and sick and medical personnel and facilities will be subjected to incidental harm as the result of an attack on a proximate military objective. However, so long as the anticipated harm is incidental, and not knowingly directed against such personnel and facilities, it is permissible, and does not implicate the proportionality assessment. Therefore, according the 2015 DoD Manual approach, a commander was forced to make a determination of whether that "reasonable idea" constitutes "knowing" an attack is directed against a protected target, and if it did, the attack was (and currently still is under the 2016 DoD Manual) legally impermissible. But if that reasonable idea did not result in a knowing the attack was directed against a protected target, the commander then had no obligation to apply a secondary restrictive proportionality assessment.

The DoD Manual's position on the inapplicability of the proportionality obligation to military wounded and sick, medical personnel, and medical facilities was, as noted above, justifiable based on the status of these individuals and objects. However, just as the ICRC Commentary approach suffers from overbreadth, the 2015 DoD Manual approach suffered from arguable under-inclusiveness. While the proportionality obligation may not technical be applicable to this context, the indication that risk to these individuals and objects is never a relevant consideration when making an attack decision seems problematic in situations where such consideration will not compromise tactical or operational effectiveness. At some point, the approach incorporated into the 2015 Manual seems too dismissive of the humanitarian rational of IHL. Should an attacking commander ever be required to factor such risk into attack decisions? Is the Manual correct in suggesting that a commander is never required to consider implementing measures to mitigate such risk? Perhaps a middle ground between the Commentary and Manual approach should be explored.

Fortunately, as will be explained in Part V, the 2016 revision of the Manual, while reiterating the inapplicability of a proportionality obligation $v i s-a ̀-v i s$ these personnel and objects, ameliorated the impact of this underinclusiveness by reconsidering the extension of precautionary measures. However, before addressing this approach to mitigating the troubling humanitarian over-breadth of complete indifference to the collateral consequences on these personnel and objects resulting from otherwise lawful attacks, it is worth considering whether basic dictates of humanity compel a middle-ground approach to this problem. 


\section{THE HUMANITARIAN BASIS FOR A MIDDLE-GROUND APPROACH}

The dichotomy between the ICRC's 2016 Commentary and the DoD Manual interpretations of the applicability of the proportionality rule to military medical personnel, wounded and sick, and units and facilities is undeniable. As indicated above, both are arguably flawed. But the Commentary's basic premise- that at some point in the complex continuum of tactical execution, efforts to mitigate this specific risk should influence a commander's attack decisions - is ultimately aligned with the humanitarian objectives of the law. The truly difficult question that either approach fails to address is the 'when' and 'why'?

Starting with the 'why,' neither the extension of the proportionality obligation, nor the respect and protect obligation, provide the most compelling answer. Perhaps there is a more credible, albeit general foundation for extending some protection against collateral consequences to these personnel and objects - basic considerations of humanity. Is this particular situation one of those rare dilemmas that the Martens Clause can help to resolve? Perhaps.

F.F. de Martens, Russian delegate to the 1899 Hague Peace Conference, is responsible for the drafting and implementation of an iconic clause present first in the Preamble to the 1899 Hague II Convention. ${ }^{61}$ The Martens Clause states:

Until a more complete code of the laws of war is issued, the High Contracting Parties think it right to declare that in cases not included in the Regulations adopted by them, populations and belligerents remain under the protection and empire of the principles of international law, as they result from the usages established between civilized nations, from the laws of humanity, and the requirements of the public conscience. ${ }^{62}$

Versions of what is today known as the Martens Clause were subsequently incorporated into the most important IHL treaties, including the 1899 and

\footnotetext{
61 Theodor Meron, The Martens Clause, Principles of Humanity, and Dictates of Public Conscience, 94 AM. J. INT’L L. 78, 79 (2000).

${ }^{62}$ Convention (II) with Respect to the Laws and Customs of War on Land and its annex: Regulations concerning the Laws and Customs of War on Land, 29 July 1899, Preamble, 32 Stat. 1779, T.S. 423.
} 
1907 Hague Conventions, the 1949 Geneva Conventions, the 1977 Additional Protocols, and the CCW. ${ }^{63}$

The Martens Clause was initially a compromise among the parties to the 1899 Hague Peace Conference regarding the controversial debate as to whether the inhabitants of an occupied territory had a right to resist the occupying forces. ${ }^{64}$ However, the significance of this provision has evolved substantially since its original adoption. Today, the Clause is recognized as an important "gap filler" to address areas of humanitarian uncertainty. ${ }^{65}$ As a matter of customary international law, the Martens Clause embodies the notion that, where no specific rule applies, the core principles of IHL arise to dictate the conduct of hostilities. ${ }^{66}$ Accordingly, perhaps a limited application of the proportionality obligation should function to protect military casualties and the personnel and equipment devoted to their care, an obligation derived from the Martens Clause.

The Martens Clause approach also helps clarify the question of 'when' a proportionality obligation arises. Specifically, only when elemental considerations of humanity justify application — considerations that account for legitimate interests of military necessity-does the obligation come into force. This interpretation allows for consideration of each tactical situation on an individual and practical basis by accounting for imposition of protection at mature medical treatment locations, but not in the midst of combat engagements. This reading balances the logic of the DoD Manual (that the

63 See Convention (IV) Respecting the Laws and Customs of War on Land, Oct. 18, 1907, Preface, 36 Stat. 2277 , T.S. 539; GWS, supra note 4, art. 63; Geneva Convention for the Amelioration of the Condition of Wounded, Sick, and Shipwrecked Members of the Armed Forces at Sea, Aug. 12, 1949, art. 62, 6 U.S.T. 3217, 75 U.N.T.S. 971; Geneva Convention Relative to the Treatment of Prisoners of War, Aug. 12, 1949, 1426 U.S.T. 3316, 75 U.N.T.S. 972; GC, supra note 34 (collectively, the Geneva Conventions); Convention on Prohibitions or Restrictions on the Use of Certain Conventional Weapons Which May be Deemed to be Excessively Injurious or to Have Indiscriminate Effects, Oct. 10, 1980, Preamble, 1342 UNTS 137. For an excellent insight into the historical origins of the Clause and the background of the Clause's author, see Jeffrey Kahn, "Protection and Empire": The Martens Clause, State Sovereignty, and Individual Rights, 56 VA. J. INT’L L.1 (2016).

64 ADAM RoBERTS \& RichaRd GUELFF, DOCUMENTS ON THE LAWS OF WAR 9 (3d ed. 2000) ("The wording of the Martens Clause was agreed at the 1899 Hague Peace Conference for a specific reason: it was a compromise following difficult and unresolved debates about whether the inhabitants of occupied territory had a right of resistance.”).

65 Kahn, supra note 63, at 18.

${ }^{66} C f$. Legality of the Threat or Use of Nuclear Weapons, Advisory Opinion, 1996 I.C.J. 226, 260 (July 8). The court specifically states, "the Martens Clause, whose continuing existence and applicability is not to be doubted, as an affirmation that the principles and rules of humanitarian law apply to nuclear weapons." Id. While the context of the advisory opinion regards the threat or use of nuclear weapons, the court's acknowledgment that the Martens Clause ensures that the principles of IHL apply to such weapons is foretelling of its vast extent. 
nature of hostilities renders it illogical to require a proportionality assessment whenever risk to these individuals and facilities is created by an attack) with humanitarian considerations (by requiring risk mitigation efforts to protect such personnel and facilities when doing so is not tactically illogical). It is noteworthy that the DoD recently published a policy letter that appears to endorse this type of Marten's Clause approach to this issue. Specifically, the Deputy Assistant Secretary of Defense for Stability and Humanitarian Affairs issued a policy titled, "Principles Related to the Protection of Medical Care Provided by Impartial Humanitarian Orgs. During Armed Conflicts."67 According to this policy letter, "[C]onsiderations of humanity, proportionality, and honor should guide combatants in all their interactions with the wounded and sick." 68

The Martens Clause is concededly general in its terms and vague in its relevance. However, it does seem to suggest that parties to armed conflict should be constantly guided by humanitarian considerations, and therefore seek to mitigate the suffering of war to only that which is justified by the dictates of military necessity. Where the ICRC seems on track is in the recognition that such a lacuna exists due to the absence of any positive proportionality protection for military wounded and sick, and the personnel, equipment, and facilities exclusively engaged in their collection and care. The Martens Clause therefore provides a logical basis for parties to a conflict to seek some operationally rational method to avoid, where feasible, unnecessary infliction of suffering on these personnel and objects. In practice, precautionary risk mitigation measures offer a more operationally logical solution to this dilemma than does extending the proportionality rule. This is because such measures would be required only when tactically and operationally feasible. Such an approach would produce a wide margin of appreciation for assessing when precautions must be employed, but would also emphasize that there is, at some point of tactical and operational logic, an obligation to seek to mitigate risk to military medical personnel and facilities. As explained below, this is precisely the approach incorporated into the 2016 revision to the DoD Law of War Manual.

\footnotetext{
${ }^{67}$ Policy Letter, Deputy Assistant Sec'y of Def. (DASD) for Stability and Humanitarian Affairs, DeP'T OF Def., subject: Principles Related to the Protection of Medical Care Provided by Impartial Humanitarian Orgs. During Armed Conflicts (Oct. 6, 2016).

${ }^{68}$ Id. at II.C.
} 


\section{THE 2016 LAW OF WAR MANUAL REVISION: EMBRACING THE PRECAUTIONS APPROACH}

After the date of the symposium for which we first addressed this issue, the Department of Defense issued an updated version of the original June 2015 Law of War Manual. This December 2016 Manual incorporates a host of revisions on punctuation and spacing, style, correction of typographical and administrative errors, as well as minor and significant substantive changes and clarifications. This update, issued just a year-and-a-half after initial publication, should be acknowledged as a positive development. The Department of Defense has demonstrated a continuing commitment to identifying areas of beneficial improvement to the Manual. This is evidenced by the Office of General Counsel's request for comment and criticism of the Manual, a request made on the same day of the Manual's initial publication. ${ }^{69}$

Since articulating the initial Martens Clause proposal, the views of the authors of this Article have also evolved. ${ }^{70}$ As a result, we now suggest protection from collateral risk to military protected persons and equipment may also be logically extrapolated from the existing treaty and customary international law rule related to precautions in the attack. Indeed, it is arguable that several of these precautions, when feasibly implemented, provide a more compelling basis to support extending this protection than the proportionality approach advanced by the ICRC Commentary. Specifically, this protection should focus on extending AP I's Article 57 feasible precautions, to include the obligation to do all that is feasible to verify the nature of intended targets in order to implement the distinction obligation (which prohibits directing an attack against wounded and sick members of the armed forces and military protected persons and equipment). Furthermore, where feasible, this obligation also requires commanders to issue warnings to enable the enemy to

69 DoD LAW OF WAR MANUAL, supra note 3, § 1.1.1 (“This manual does not, however, preclude the Department from subsequently changing its interpretation of the law.”); U.S. DEP'T of Defense, Dir. 2311.01E, DoD LaW OF WAR, Program (9 May 2006, current 22 Feb. 2011).

70 This Article was originally written in October 2016, several months before the release of the updated December 2016 DoD Law of War Manual. At that time, the authors thought the Martens Clause to be one credible approach by which to alleviate the disparity between the ICRC and DoD approaches. However, the extremes of this disparity were substantially alleviated when the Department of Defense subsequently published a significant change in the revised Law of War Manual that addressed this specific issue.

Released in December 2016, precautionary measures emerged as the DoD solution to the challenge of protecting military wounded and sick, medical personnel, and equipment and facilities from the collateral effects of otherwise lawful attacks. 
mitigate collateral risk; and again, where feasible, employ methods or means of attack that also mitigate that risk.

Interestingly, this is the new approach adopted by the U.S. Department of Defense for balancing the competing interests associated with this collateral risk problem. This is reflected in the updated 2016 DoD Manual, which, when addressing the protection of military protected persons and assets, no longer contains the line "they need not be considered as incidental harm in assessing proportionality in conducting attacks," ${ }^{, 71}$ and instead clarifies in 7.3.3.1, and similarly in 7.8.2.1 ${ }^{72}$ and 7.10.1.1. ${ }^{73}$ that:

The respect and protection due to the wounded, sick, and shipwrecked do not prohibit incidental damage or casualties due to their proximity to military objectives or to a justifiable mistake. Combatants who are wounded, sick, or shipwrecked on the battlefield are deemed to have accepted the risk of death or further injury due to their proximity to military operations. Although the presence of the wounded, sick, or shipwrecked on the battlefield does not serve to exempt military objectives from attack due to the risk that such personnel would be incidentally harmed, feasible precautions must be taken to Although the presence of the wounded, sick, or shipwrecked on the battlefield does not serve to exempt military objectives from attack due to the risk that such personnel would be incidentally harmed, feasible precautions must be taken to reduce the risk of harm to the wounded, sick, or shipwrecked. ${ }^{74}$

In support of this asserted precautions obligation, the 2016 DoD Manual cites back to the section addressing the obligation to take feasible precautions to mitigate risk to civilians and civilian property, which in turn relies on Article 57 of AP I. ${ }^{75}$ In one respect, using Article 57 as the foundation for extending precautionary measures to such individuals and assets may seem somewhat inconsistent with the rejection of extending the proportionality rule of AP I to the same people and objects, as a proportionality assessment

\footnotetext{
71 Dod Law OF War Manual, supra note 3, § 7.3.3.1. See also id. § 7.8.2.1, 7.10.1.1.

72 See supra note 58 and accompanying text (for a comparison between the language of the 2015 and 2016 Manuals).

73 See supra note 56 and accompanying text (for a comparison between the language of the 2015 and 2016 Manuals).

${ }^{74}$ DoD LAW OF WAR MANUAL, Dec. 2016 ed., supra note 2, $§ 7.3 .3 .1$; see also supra note 53 and accompanying text (for a comparison between the language of the 2015 and 2016 Manuals).

${ }^{75}$ DoD LaW OF WAR Manual, Dec. 2016 ed., supra note 2, $§$ 5.10.1.2.
} 
is one of the precautions enumerated in Article 57. The Manual does not explicitly explain why it rejects the extension of one rule applicable by its terms only to civilians (i.e., proportionality), but then indicates that during attacks, feasible precautionary measures must be implemented to mitigate risk to military protected persons and equipment.

There is, however, a plausible textual basis for this partial application of Article 57's precautions - the target verification precaution in Article 57(2). Article 57(2)(a) states:

With respect to attacks, the following precautions shall be taken:

a) those who plan or decide upon an attack shall:

i) do everything feasible to verify that the objectives to be attacked are neither civilians nor civilian objects and are not subject to special protection but are military objectives within the meaning of paragraph 2 of Article 52 and that it is not prohibited by the provisions of this Protocol to attack them;

ii) take all feasible precautions in the choice of means and methods of attack with a view to avoiding, and in any event to minimizing, incidental loss of civilian life, injury to civilians and damage to civilian objects;

iii) refrain from deciding to launch any attack which may be expected to cause incidental loss of civilian life, injury to civilians, damage to civilian objects, or a combination thereof, which would be excessive in relation to the concrete and direct military advantage anticipated; ${ }^{76}$

Article 57(2)(a) includes within its terms protection not only of civilians and civilian objects, but also people and places subject to "special protection."

This "special protection" basis for requiring the target verification precaution, but not a proportionality precaution, is bolstered by the text of Article 57(2)(b), which requires that an attack be cancelled or suspended when it becomes apparent that an intended target is subject to "special protection.”

(b) an attack shall be cancelled or suspended if it becomes apparent that the objective is not a military one or is subject to special protection or that the attack may be expected to cause

${ }^{76}$ AP I, supra note 2, art. 57(2)(b) (emphasis added). 
incidental loss of civilian life, injury to civilians, damage to civilian objects, or a combination thereof, which would be excessive in relation to the concrete and direct military advantage anticipated; ${ }^{77}$

The key to the application of the feasibility precaution, but not the proportionality precaution, lies within the text of the "civilian" component to Article 57(2)(b). Note that an attack must to be cancelled or suspended based on a proportionality violation - "that the attack may be expected to cause incidental loss ... excessive in relation to the concrete and direct military advantage anticipated" - only when the attack will endanger civilians, civilian property, or a combination of the two. This qualifier is not present and applicable to those persons and objects enjoying "special protection," which is only led by a qualifier indicative of keeping them from being the deliberate intended target of attack.

Going back to the earlier portrayed hypothetical engagement between the United States and Iraq, ${ }^{78}$ the feasibility element to the precautionary measures approach provides a more rational answer than the extension of the proportionality rule. After the American's first salvo, halting or even pausing a subsequent attack on the Iraqi position in order to mitigate risks to enemy wounded personnel and those tending to them would hardly be considered feasible. Therefore, unlike under the proportionality approach proffered by the ICRC Commentary, a feasibility approach would not inhibit the U.S. commander's ability to press tactical advantage and set the tempo of the engagement in order to maximize the collective impact on the Iraqi force.

Furthermore, the feasible precautions approach does not ignore other tactical situations where protection may be feasibly extended to wounded and sick members of the armed forces and military protected persons and equipment. For example, it is quite common for military units to co-locate medical aid stations and other forward collection and treatment facilities in military logistics clusters. This cluster method better facilitates the rapid reconstitution of resources with the backhaul of casualties. However, this also means that an attack on the logistics cluster itself jeopardizes inflicting collateral damage to the medical aid station and collection and treatment facilities, as well as their occupants. In this context, precautions related to the means and methods of attack could not only be feasibly implemented, but could mitigate risks to the aid station and its occupants. The feasible precautionary measures approach, therefore, strikes an appropriate balance,

77 See supra pp. 456-67 and accompanying text.

${ }^{78}$ ICR to that engagement on pp. 12-13. 
and as referenced earlier from the clear articulation of the UK Law of War Manual, aligns with the spirit of IHL: "The law of armed conflict is consistent with the economic and efficient use of force. It is intended to minimize the suffering caused by armed conflict rather than impede military efficiency."79

There is another reason why the feasible precautions approach adopted by the 2016 DoD Manual is more credible than the proportionality approach from the ICRC Commentary-the inclusion of the GWS's Article 21 precautions-type rule for the protection of military medical facilities. Article 21 of the GWS provides:

The protection to which fixed establishments and mobile medical units of the Medical Service are entitled shall not cease unless they are used to commit, outside their humanitarian duties, acts harmful to the enemy. Protection may, however, cease only after a due warning has been given, naming, in all appropriate cases, a reasonable time limit and after such warning has remained unheeded. ${ }^{80}$

While not expressly phrased as a precautionary measure, this warning obligation applicable to military medical facilities indicates that the drafters of the GWS contemplated situations where subjecting the occupants of such facilities to the risks of attack may be unavoidable. However, because it will almost always be the case that an attack in response to misuse of such a facility will subject the other still protected persons in the facility to incidental death and injury, the GWS imposed a precautionary warning obligation. This is notable for two reasons: first, it is a clear indication that the logical method to mitigate this risk was through the issuance of an appropriate warning; second, there is no indication that an attacking force must apply a proportionality assessment once it determines that attack is necessary because the enemy fails to cease the misuse after the warning.

Ultimately, the "precautions" approach is based on a more logical treaty foundation than the ICRC Commentary "proportionality" approach. And this is an especially important and positive development for the U.S. military that will hopefully be more commonly embraced, as it strikes a logical balance between the risks that wounded and sick members of the armed forces and military protected persons and equipment must accept as the result

\footnotetext{
${ }^{79}$ U.K. Ministry of Defence, The Joint Service Manual on the Law of ARmed CoNFLICT, JSP 383, para. 2.1, at 21 (2004), https://www.gov.uk/government/uploads/system/ uploads/attachment_data/file/27874/JSP382004Edition.pdf.

${ }^{80}$ GWS, supra note 16 , art. 21.
} 
of their association with an armed force, and the interests of humanity that make complete indifference to this risk unacceptable.

\section{CONCLUSION}

Seeking to extend the protection derived from the proportionality rule to military wounded and sick and non-combatant members of the armed forces (and their facilities) is in no way illogical. Indeed, most observers would likely consider completely indifference the collateral consequences of attacks that jeopardize these individuals and objects as inconsistent with basic dictates of humanity. However, what appears appealing on the surface becomes increasingly inconsistent with the equally important considerations of military necessity as the drill penetrates the depths of application analysis.

Basing an extension of the proportionality obligation on the respect and protect obligation cannot withstand scrutiny. More importantly, it is not an ideal answer to the question of how to mitigate incidental and collateral risks to wounded and sick members of the armed forces, as well as the military personnel, facilities, and transportation exclusively engaged in their collection and care. However, rejecting any consideration of the risks to these individuals, objects, and facilities based on the textual contexts of the proportionality rule produces an overly-broad dismissal of this humanitarian concern. Ultimately, it is probably true that there may not be an ideal solution to resolving the dilemma created the failure of positive treaty law to expressly address why such risk should be mitigated; it may simply be impossible to reconcile the logical humanitarian goal of mitigating risk to such personnel and facilities with existing positive legal obligations.

Addressing this issue need not, however, be dictated by the binary interpretations of the scope of the proportionality obligation reflected in these two extremes. Instead, a rational balance between military necessity and the dictates of humanity may be achieved by extending the feasible precautions methodology enumerated in Article 57 of AP I as adopted by the updated 2016 DoD Law of War Manual. Requiring risk mitigation measures when operationally and tactically feasible-meaning such measures will not meaningfully compromise the interests of military necessity-seems to be a logical approach to achieving an acceptable balance to protect such individuals and objects from unnecessary collateral risks. Furthermore, in comparison to the ICRC Commentary proportionality extension, this approach is better aligned with the GWS Article 21 rule related to the misuse of military medical facilities. It is also better aligned with the instincts of military commanders. After all, why would any commander forego the opportunity to reduce risk to wounded and sick combatants and non- 
combatant members of the armed forces when doing so in no way compromises or degrades his or her efforts to achieve military objectives and defeat enemy forces?

Such a resolution is bolstered by its consistency with the interests reflected in the Martens Clause. This approach is certainly no talisman, and cannot eliminate all uncertainty related to when the protection applies and how it is best implemented. However, it will at least eliminate the risk that combatants completely ignore risk to the wounded, sick, military medical personnel, and facilities when planning and executing combat operations. Ultimately, indifference towards these personnel and facilities is almost impossible to reconcile with the dictates of "public conscience." As such, the shadow of Feodor Martens may be broad enough to cover this space. 